\title{
Enhancing PASS leaders' employability skills through reflection
}

\section{Amanda Zacharopoulou}

Ulster University, UK

\section{Melanie Giles}

Ulster University, UK

\section{Joan Condell}

Ulster University, UK

\section{Abstract}

Whilst the benefits for students attending Peer Assisted Study Sessions (PASS) have been widely acknowledged, the benefits for its leaders have not been as clearly evaluated. This paper will explore how the more senior students who take on the role of PASS leader can develop employability skills through a programme of activity that formally rewards students for their participation and assists them in articulating their competencies. The paper presents the findings of a project undertaken by a cross-disciplinary team at Ulster University which focused on the benefits for PASS leaders and, more explicitly, on graduate employability skills such as communication, teamwork and leadership. Students were required to reflect on the PASS process and plan for subsequent sessions whilst also engaging in a series of skill-building activities (games and various practical exercises) which focused on those facets of employability that are of direct relevance to the PASS experience. Quantitative and qualitative methods were employed to evaluate the impact of the PASS programme: initial findings suggest that the programme served to enhance students' perceived competence in respect of some employability skills (e.g. spoken communication) but, more generally, served to raise their awareness and highlight their limitations in some areas. This paper suggests that the process of reflection has helped them to better articulate these skills and identify the steps needed to further develop them. As such, this project has provided research evidence to support the effectiveness of the PASS process and a collection of materials to support the further development of its leaders. 
Keywords: employability; PASS; graduate skills; professional development.

\section{Introduction}

The recent Wilson Review (2012), focusing on business-university collaboration, recommended that universities should be reflecting on the opportunities that students have to develop their employability skills. The review highlighted the fact that:

The CBI Education and Skills Survey 2011 found that 82 percent of employers surveyed rated employability skills as the highest graduate recruitment factor. Selfmanagement, teamwork, problem solving, communication skills, application of IT, application of numeracy all featured consistently in employer needs. (Wilson, 2012, p.31).

The National Centre for Universities and Business (NCUB) in their annual 'State of the Relationship Report' (2014) points out the significance of continuous professional development 'to help bring about the rounded graduate' (2014, p.6). Moreover, it is now accepted that employability is part of good pedagogy (Pegg et al., 2012): student learning should be viewed as a holistic experience in which many forces operate to encourage students to become confident learners who will be able to contribute effectively to society upon graduation (Pascarella and Terenzini, 2005).

Harvey presents employability as being:

More than about developing attributes, techniques or experience just to enable a student to get a job, or to progress within a current career. It is about learning and the emphasis is less on 'employ' and more on 'ability'. In essence, the emphasis is on developing critical, reflective abilities, with a view to empowering and enhancing the learner' (Harvey, 2005, p.13).

This encourages a shift away from the more traditional, narrow skills focus when defining employability, and provides a clearer recognition of a reflective, student-centred approach in developing employability: 
Which encompasses the value of learning in higher education as enabling and creative. (Pegg et al., 2012, p.5).

Here at Ulster, we have turned to the PASS initiative as a way of promoting effective learning and enhancing employability for students. PASS (Peer Assisted Study Sessions) is a teaching initiative derived from the American model of 'Supplemental Instruction' (SI) developed at the University of Missouri, Kansas in 1973. Adapted for use in the UK and renamed PASS, this internationally renowned initiative, involves using senior students to facilitate group learning in an informal environment. Its purpose is to support the student experience through collaborative exploratory discussion and in so doing, improve academic performance and achievement and reduce student drop-out. It also enhances the learning experience and personal development of PASS leaders thereby enhancing their employability and provides an additional mechanism for communication and feedback between teaching staff and students and serves to foster a sense of commitment and belonging. Based on the philosophy of 'tell me and I forget, show me and I remember, involve me and I understand', PASS promotes an active approach to learning and teaching and has been shown to enhance performance by engaging students more explicitly with their academic discipline (see e.g. Ashwin, 1994) and promote the development of skills and attributes to strengthen employability (Skalicky and Caney, 2010). However, mindful of the need to assist students in articulating these skills, we also realised the importance of reflection. Thus, in line with the thinking of Jarvis et al. (2013), we used the process of reflection to help our students understand how they are learning and relate their learning to a wider context.

\section{The PASS leader programme}

The success of PASS is built on the thorough training of PASS leaders, regular debriefing sessions with teaching staff and formative evaluation enabling progressive changes in the process. Whilst our training programme is broadly consistent with the PASS approach, the workshops and debriefs were designed to focus more explicitly on graduate employability skills such as communication, teamwork and leadership. As such, leaders first received a compulsory one-day course followed by two discipline-specific workshops. They then enrolled for two modules, one per semester. The modules were designed to assess a range of outcomes some of which are specific to the process (e.g. their ability to plan, 
deliver and evaluate a PASS session; apply relevant learning strategies to enhance learning; employ a range of collaborative learning techniques to facilitate group discussion) and others which are more generic (e.g. their ability to communicate effectively and reflect on their personal development). These more generic employability skills were further developed during the weekly debriefs. Thus each week students were required to reflect on the PASS process and plan for subsequent sessions whilst also engaging in a series of skill-building activities (games and various practical exercises) focused on those facets of employability that are of direct relevance to the PASS experience (e.g. listening skills, interpersonal communication, teamwork, time management, problems solving, creative thinking etc). The two co-curricular modules were initially designed as a component of our Certificate of Personal and Professional Development (CPPD) and are now a recognised component of the EDGE award, a recent initiative designed to enhance the employability of Ulster students by providing engagement with, and official recognition of, extracurricular and co-curricular achievements.

\section{Aim}

Mindful of the need to make better use of student engagement initiatives to enhance the employability of our students, to assist them in articulating their skills and also to reward them for their participation as peer mentors, we developed a programme of activity that is broadly consistent with the PASS approach, but is designed to focus more explicitly on graduate employability skills such as communication, teamwork and leadership. As such, the aim of this project has been to evaluate a programme of activity designed to:

- Enhance the employability skills of our students and to help them articulate the skills they have gained during their time as a PASS leader, thus making the implicit more explicit.

- Formally reward PASS leaders for their participation in the PASS programme by refining two co-curricular modules that could be delivered as part of the personal and professional development scheme within the university. 


\section{Method}

\section{Design}

To evaluate the effectiveness of this programme both quantitative and qualitative methods were employed, not only to explore the benefits and shortcomings of the PASS process from the leaders perspective but ultimately, to assess its impact on employability. Specifically, a questionnaire survey was administered to all second year students in participating disciplines at the beginning and towards the end of the process, thereby allowing for a comparison between PASS leaders and the rest of the student cohort. Focus group interviews were also conducted and students were encouraged to reflect on the process during the weekly PASS and debrief sessions and in written assignments. A steering group comprising faculty coordinators, a placement officer and other student representatives, also met regularly to monitor and review progress.

\section{Participants}

Participants were recruited from the second year cohorts of both the School of Law and the School of Psychology. For the questionnaire survey, 50 participants (7 males, 43 females) aged 19-37 years completed questionnaires at two points in time. Of these, 23 were PASS leaders. Focus group interviews were conducted with 6 groups of students, with each group comprising between 5 and 7 people. The selection of participants was based on an availability sample and included a mix of PASS leaders and other second year students not involved in the PASS scheme. Further, 36 PASS leaders from both schools were required to reflect on their experiences, of whom 11 were male and 25 were female.

\section{Procedure}

The PASS leaders' perceptions of the scheme were assessed using both quantitative and qualitative methods. Specifically, the following methods were employed: (i) a questionnaire survey, (ii) focus group interviews and (iii) reflections submitted as part of the module assessment process. Ethical approval for the data collection was granted by the Ulster University Ethics Committee. 
Questionnaire survey: The questionnaire survey focused specifically on the concept of employability and included 63 items focused on 10 facets including for example teamwork, leadership, presentation skills and time management. Six questions were used to assess each facet; a 6-point response format was employed ranging from 'definitely agree' to 'definitely disagree'. Thus, to assess students' perceptions of their team working skills for example, they were asked to respond to questions of the form: 'I am able to work effectively as part of a team' and 'I can collaborate well with others'. Similarly with respect to presentation skills, participants were asked to respond to statements like: I am able to express myself clearly and concisely to a group of people' and 'I can prepare plans and deliver a presentation' (see Table 1).

Table 1. Details of the employability measure.

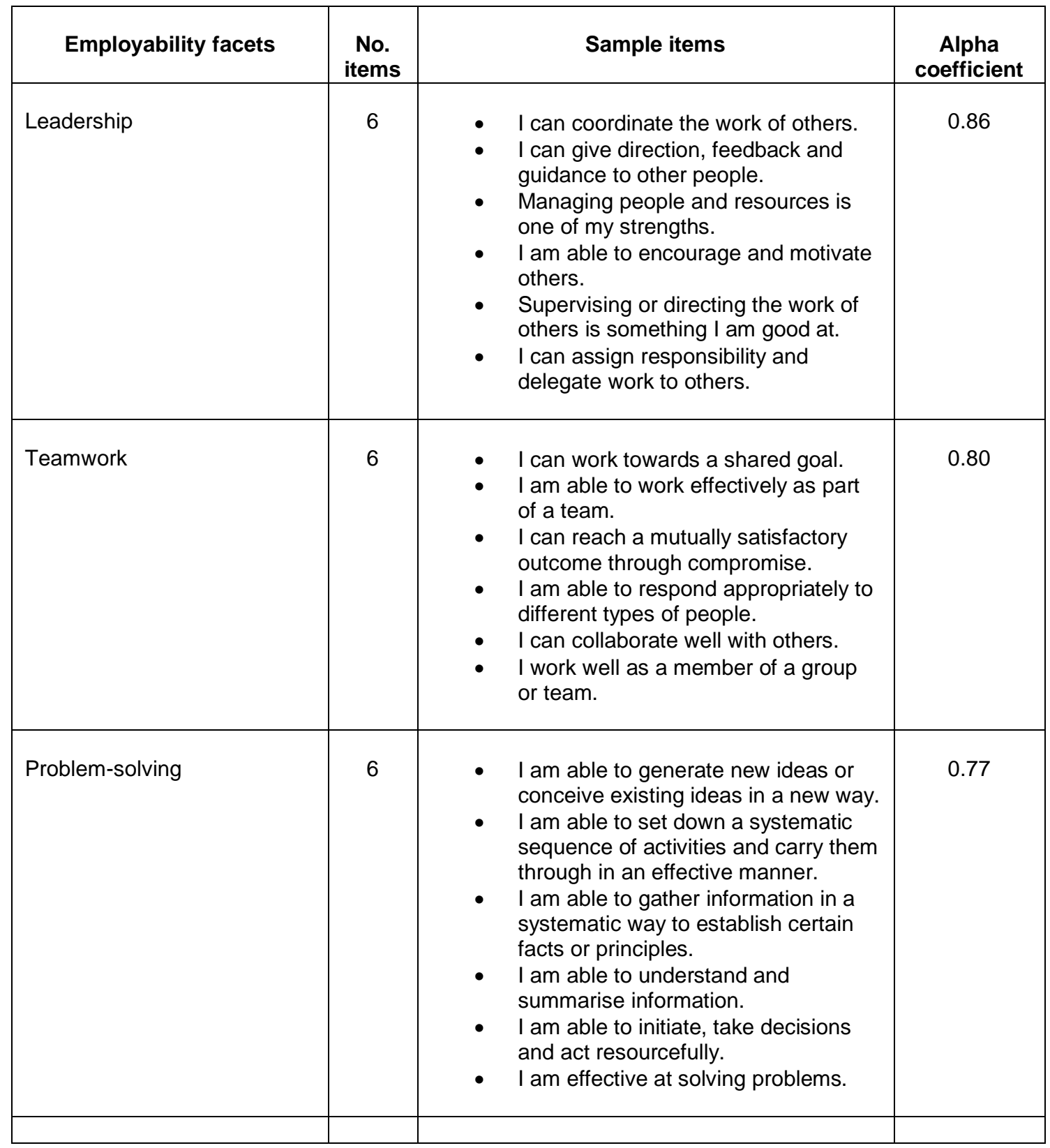




\begin{tabular}{|c|c|c|c|}
\hline Written Communication & 6 & $\begin{array}{l}\text { - I am able to express myself well in } \\
\text { writing. } \\
\text { - I can punctuate, use grammar and } \\
\text { spelling correctly. } \\
\text { - I am confident in my ability to present } \\
\text { my ideas in written form. } \\
\text { - I am able to adapt my writing styles } \\
\text { to suit the appropriate } \\
\text { media/audience. } \\
\text { - I can produce a written plan to } \\
\text { answer an assignment question. } \\
\text { My written communication skills are } \\
\text { good. }\end{array}$ & 0.86 \\
\hline Spoken Communication & 6 & $\begin{array}{l}\text { - I can communicate easily with other } \\
\text { people. } \\
\text { - I am able to express myself clearly } \\
\text { and concisely to a group of people. } \\
\text { - I can prepare, plan and deliver a } \\
\text { presentation. } \\
\text { - I am confident speaking in front of a } \\
\text { group of people. } \\
\text { - I am able to express my views } \\
\text { verbally. } \\
\text { - I can communicate well with others. }\end{array}$ & 0.91 \\
\hline Listening & 6 & $\begin{array}{l}\text { - I am able to listen to and appreciate } \\
\text { the views of others. } \\
\text { - I find it hard not to interrupt when } \\
\text { others are speaking. } \\
\text { - I am able to match my body } \\
\text { language appropriately to what is } \\
\text { being said. } \\
\text { - I tend to wait until the other person } \\
\text { has finished speaking before } \\
\text { responding. } \\
\text { - I am able to respond appropriately to } \\
\text { others' comments during a } \\
\text { conversation. } \\
\text { - I am a good listener. }\end{array}$ & 0.63 \\
\hline Time Management & 6 & $\begin{array}{l}\text { - I am able to allocate my time } \\
\text { efficiently. } \\
\text { - } \quad \text { I am able to manage several tasks at } \\
\text { the same time. } \\
\text { - I am good at meeting deadlines. } \\
\text { - I am able to prioritise tasks and set } \\
\text { appropriate timelines. } \\
\text { I can set goals and monitor } \\
\text { progress. } \\
\text { I have effective time management } \\
\text { skills. }\end{array}$ & 0.84 \\
\hline Self-Management & 6 & $\begin{array}{l}\text { - I am able to identify my personal } \\
\text { goals. } \\
\text { - I am a good judge of what my } \\
\text { strengths and areas of development } \\
\text { are. } \\
\text { - I am able to identify opportunities for } \\
\text { learning outside my course. } \\
\text { - I am able to plan for my personal } \\
\text { development. } \\
\text { - I can accept responsibility. } \\
\text { I can evaluate and monitor my }\end{array}$ & 0.80 \\
\hline
\end{tabular}




\begin{tabular}{|c|c|c|c|}
\hline & & personal performance. & \\
\hline Creativity & 6 & $\begin{array}{l}\text { - I can adapt to situations of change. } \\
\text { - I can provide novel solutions to } \\
\text { problems. } \\
\text { - I know how to initiate change to } \\
\text { enhance productivity. } \\
\text { - I like inventing things. } \\
\text { - I am always thinking of new ways of } \\
\text { doing things. } \\
\text { I am a creative person. }\end{array}$ & 0.72 \\
\hline Personal Growth & 9 & $\begin{array}{l}\text { - I know how to change specific things } \\
\text { that I want to change in my life. } \\
\text { - I have a good sense of where I am } \\
\text { headed in my life. } \\
\text { - If I want to change something in my } \\
\text { life, I initiate the transition process. } \\
\text { - I can choose the role that I want to } \\
\text { have in a group. } \\
\text { - I know what I need to do to get } \\
\text { - I I have a specific action plan to help } \\
\text { - I take charge of my life. } \\
\text { - I know what my unique contribution } \\
\text { to the world might be. } \\
\text { I have a plan for making my life more } \\
\text { balanced. }\end{array}$ & 0.90 \\
\hline
\end{tabular}

The questionnaire was designed specifically for use in this study and thereby to assess the extent to which PASS had served to enhance the employability skills of our students. Reliability was assessed using Cronbach's alpha and values ranging from 0.63 (listening) to 0.91 (spoken communication) were obtained. Students were also asked to provide information about their involvement with the PASS process and other extra-curricular activities including work experience, thereby enabling us to employ statistical techniques to objectively determine the impact of PASS on different aspects of employability.

Focus group interviews: Focus group interviews were conducted with 6 groups of participants ( 3 in each participating discipline which comprised the Schools of Psychology; Law; Computing and Intelligent Systems), with each group comprising between 5 and 7 people, thereby allowing us to explore the concept of employability in more depth. As such, participants were asked to comment generally on a range of issues including their general perceptions of the PASS process. The focus group moderator had experience of facilitating group discussions and was independent of the PASS team. All focus groups were recorded and subsequently transcribed verbatim. 
Students reflections: Thirty-six PASS leaders (24 from the School of Psychology, 12 from the School of Law) were expected to enrol on two specific modules and were formally assessed on a range of activities including: a reflective diary in which they recorded their experience of the PASS and debrief sessions; a written review of the PASS process in which they were required to demonstrate an awareness of how they had developed as a result of training; a portfolio of session plans in which they were required to identify the content to be covered and the process/strategies to be employed during their PASS sessions and, finally, a practical facilitation of a PASS session. The research team sought permission to use the reflections in the evaluation process.

\section{Results}

To reiterate, the aim of this project was to evaluate the effectiveness of a programme of activity designed to enhance the employability skills of a group of PASS leaders. ANOVAs (analysis of variance tests) were used to explore changes in mean scores on the various employability dimensions and a content analytic approach was used to analyse the transcripts emerging from the focus group discussions, which involved the extraction of key themes (Morse and Field, 1996).

\section{Quantitative findings}

A $2 \times 2$ mixed ANOVA was conducted to determine whether PASS leaders differed from non-PASS leaders on each employability facet across time. Mean scores are displayed in Table 2 (see also Figure 1).

Table 2. Mean scores for PASS leaders on each employability dimension.

\begin{tabular}{|c|c|c|c|}
\hline Leadership & 4.536 & 4.355 & 4.355 \\
\hline Teamwork & 5.065 & 4.840 & 4.840 \\
\hline
\end{tabular}



3. Problem-solving
4. Written Communication
5. Spoken Communication
6. Listening
7. Time Management
8. Self-Management
9. Creativity
10. Personal Growth

$4.659 \quad 4.644$

$4.644 \quad 4.666$

$4.818 \quad 4.608$

$4.608 \quad 4.672$

$4.558 \quad 4.630$

$4.630 \quad 4.456$

$4.985 \quad 4.791$

$4.791 \quad 4.705$

$4.834 \quad 4.669$

$4.669 \quad 4.761$

$4.761 \quad 4.579$

$4.579 \quad 4.538$

$4.215 \quad 4.204$

$4.204 \quad 4.388$

$4.347 \quad 4.376$

$4.376 \quad 4.222$

The findings suggest that whilst there were some changes in mean scores (e.g. with respect to spoken communication) the differences were not significant. Moreover, the general pattern of responding suggests that PASS leaders actually perceived themselves to be less competent in some areas at time 2 than at time 1, although they did perceive themselves to be generally more competent than non-PASS leaders across all dimensions at the beginning of the process.

Figure 1. Mean scores for PASS leaders on employability facets at time 1 and time 2.

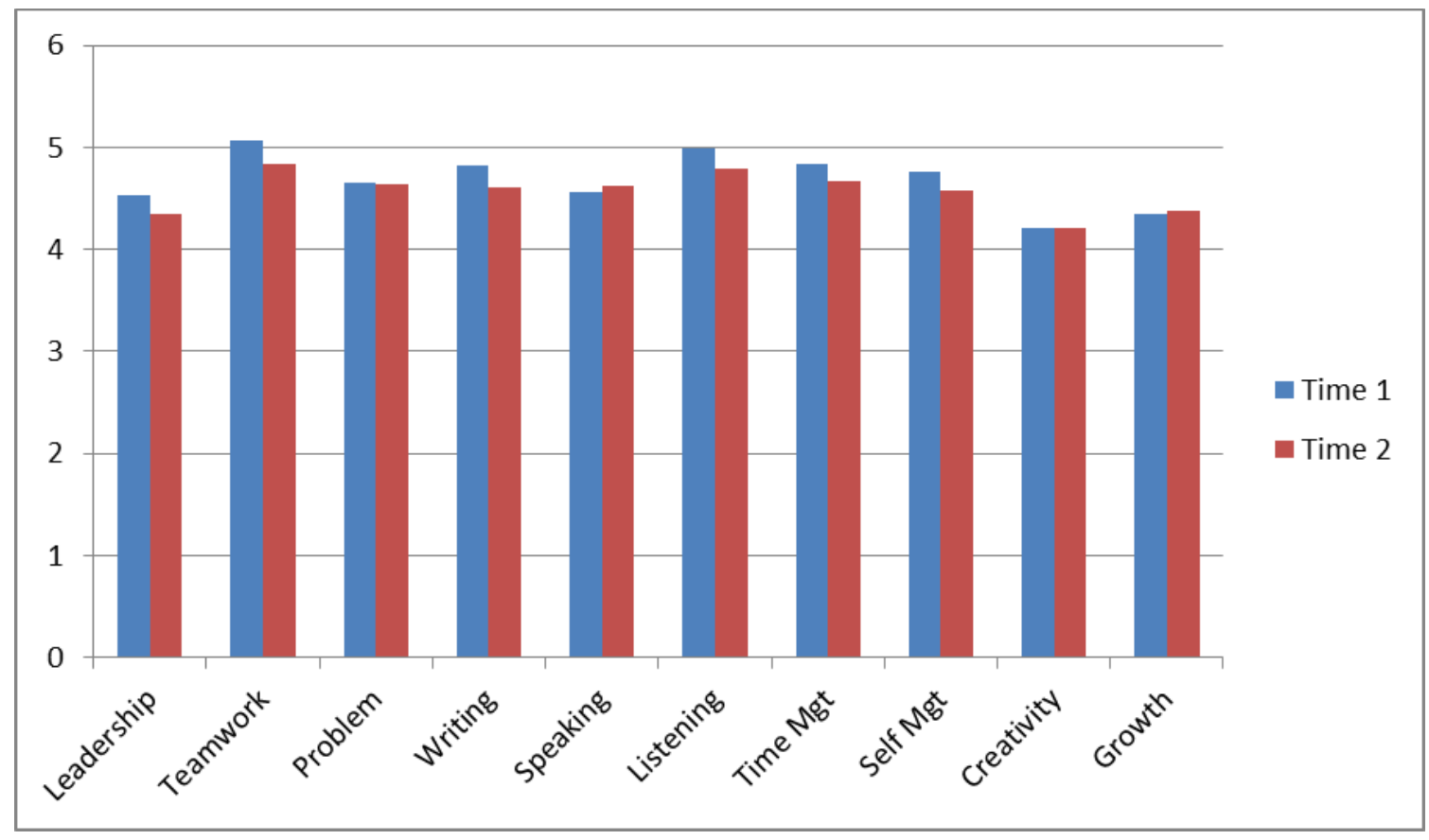




\section{Qualitative findings}

In spite of the above and consistent with previous research (see e.g. Skalicky and Caney, 2010) the qualitative findings did suggest that PASS leaders perceived themselves to have benefited from the employability initiative. From the transcripts, two main themes emerged relating to 'key skills' and 'personal development' (see Table 3).

Table 3. Themes and subthemes emerging from the focus group interviews.

\begin{tabular}{|l|l|}
\hline Themes & Sub-themes \\
\hline 1. Key Skills & $\begin{array}{l}\text { - Teamwork } \\
\end{array}$ \\
& $\begin{array}{l}\text { - Presentation skills } \\
\text { - Time management }\end{array}$ \\
& $\begin{array}{l}\text { - Confidence } \\
\end{array}$ \\
\hline 2. Personal Development & $\begin{array}{l}\text { - Employability } \\
\end{array}$ \\
\hline
\end{tabular}

In relation to skills, PASS leaders reported that the scheme had allowed them to develop in a number of ways, for example, in relation to teamwork, presentation skills, and time management, although an increase in confidence was highlighted by many as the most significant benefit:

It builds your confidence ... it is good to keep up because there are quite a few things you forget from the year before so you are refreshing yourself all the time as well ... PASS sessions were great revision classes for myself.

I feel the experience was an extremely good one, which I enjoyed, and I can see it has boosted my confidence as I can talk to people more easily now than I could before. I also feel the experience will benefit me when it comes to future employability as it shows that I can work well with others, as well as alone, that I am approachable and friendly. It also demonstrates that I have good time management skills as I achieved everything I planned. 
The two skills I believe I have developed the most as a result of being involved in PASS are effective communication and self-confidence, which will help me greatly when seeking future employment.

In relation to time management, students also commented:

You need to be good with your time. Before I started PASS I was dreadful, like l'd be late for everything. But then whenever you know that people are depending on you, you are there on time.

Well it helped with planning your sessions, organisation skills, time keeping and speaking in front of people...it helped us gain confidence, as we had to speak in front of our PASS class and in front of the other PASS leaders.

Students also recognised the importance of the process for developing their presentation and communications skills:

In debrief we covered things like interview skills and tips, presentation skills as well, and we were always feeding back so we just got used to getting up in front of a room and presenting your poster or whatever it was you created.

When I was asked if I would be interested in becoming a PASS leader I was quite indecisive as I was worried about talking in front of a group of people and didn't think I would be very good at it ... but all in all, I feel it has been a really beneficial scheme ... it has enabled me to recap on first year topics and has given me a sense of achievement when helping others. It has also given me a great confidence boost and I now have no worries about leading a group.

And in relation to teamwork:

It also gave me valuable experience as a facilitator and as a team member, from meeting my co-leader to planning and organising weekly sessions to taking part in group discussions. These were all key experiences for me. 
As a leader I found the PASS sessions were great revision classes for myself. It also gave me valuable experience as a facilitator and as a team member, and in terms of organising myself for weekly sessions and developing my leadership skills.

I think it has really helped me personally in that now I can see the lecturers like whenever our seminar teacher is telling us stuff then I can work out why they're putting us into groups or why they're doing things in a particular way.

However, the scheme was not solely focused on skills development but rather also sought to encourage leaders to reflect on their experience and to perceive how it could benefit them in the future. Lees observes that:

Reflective thinking refers to the capacity to develop critical consideration of ones' own world-view and the relationship to the world-view of others. (Lees, 2002, p.8).

When students were asked to think or reflect about the PASS scheme, what they had done and how it had helped them, significantly, all PASS leaders perceived themselves to be more employable as a result of having participated in the process. For example:

It improves your communication skills and it's good for your CV.

PASS has also helped me develop skills. Although I thought I already had them it made me realise how much more I had to develop on those skills such as working within a team and group activities, learning to include everyone and not try and take on the task entirely myself.

I believe that being a PASS leader will have a positive impact on my future employability. Preparing for and facilitating weekly group sessions and attending debrief sessions, illustrates my commitment to the process and demonstrates that I can be relied upon. Availing of the opportunity to be a PASS leader demonstrates to future employers that I showed initiative by taking an opportunity to further develop personally and also enhance my employability skills. The two skills I believe I have developed the most as a result of being involved in PASS are effective communication and self-confidence which will help me greatly when seeking future employment. 
Whilst it is clear that 'the elusive quality of employability makes it a woolly concept to pin down' (Cranmer, 2006, p.172) it is generally accepted that, irrespective of its definition, developing graduate employability has emerged as a key aim of higher education establishments. It is perhaps a little too early to comment on the impact of this work given the evaluation has only just been completed. However, we have been able to show that the scheme is having a positive impact on employability having served to enhance students' perceived competence in some areas (e.g. spoken communication), and more generally has helped them to identify their deficiencies in respect of certain employability skills and the steps needed to achieve competence in these areas.

Specifically, the quantitative data suggests that whilst leaders do perceive themselves to have enhanced their competence in some areas (e.g. with respect to spoken communication), for some skills, a decrease in mean scores was apparent between times one and two. In terms of teamwork, for example, whilst the mean score at time one was slightly higher for PASS leaders compared to the rest of the student cohort (5.06 compared to 4.87) attributable, we think, to the timing of data collection (i.e. following the initial training period) and a sense of illusory superiority on the part of leaders, their mean score had reduced to 4.81 by time two, which was also slightly lower than the non-PASS comparison group (4.94). Although most of the differences observed were not significant, the general pattern of responding suggests that, in the context of learning theory and in particular the 'conscious competence learning model' developed by Noel Burch in the 1970's, most participants were initially at stage one i.e. 'unconscious incompetence' and were thus unaware of the nature and relevance of the skills covered and the extent of their deficiencies. However, the programme served to move leaders to the second stage of 'conscious incompetence' whereby they became aware of the existence, complexity and relevance of the various skills but also of their apparent deficiencies, hence the reduction in mean scores observed (as may happen when learning to drive a car). Whilst the length of the programme was not sufficient to allow students to practice the skills to the extent that they achieved 'unconscious competence' or mastery, the process of reflection did enable them to better articulate these skills and to identify other opportunities to further develop them. Indeed, the qualitative findings would support this. 


\section{Conclusions}

Of course, it is important to acknowledge that the sample size achieved in the present context was relatively small, which limits the conclusions that can be drawn from the statistical analyses. Certainly, more research is needed with a larger sample to confirm the findings of this study. Nevertheless, it seems feasible to suggest that whilst the PASS experience does have a positive impact in terms of enhancing employability, it is not in itself sufficient to ensure mastery of all of the associated employability skills. To truly achieve competence, PASS leaders must firstly understand the benefit of a particular skill or ability and its complexity and must recognise the relevance of their own 'incompetence' or limitations with respect to the skill concerned. This process is consistent with Yorke's claim that:

Employability goes well beyond the notion of key skills, and is evidenced in the application of a mix of personal qualities and beliefs, understandings, skilful practices and the ability to reflect productively on experience. (Yorke, 2006, p.13).

The process of reflection would seem to be particularly important here in terms of helping students to identify their own development needs and the opportunities to do something about them. By continually reflecting on where and how they are using the skills, by watching and monitoring their progress, the skill will eventually become second nature. However, regular reflection and review should prevent complacency. Of course, this has implications for skill development beyond the PASS initiative.

The USEM model of employability (Yorke and Knight, 2006; Knight and Yorke, 2004) comprises four key components of Understanding, Skills, Efficacy Belief and Metacognition. Yorke and Knight are concerned that students should be able to demonstrate metacognition (capacity for reflection) and thus become malleable learners, as opposed to fixed, believing that they can take action to enhance their own abilities and hence enhance their employability. The PASS process can be used in such a way as to develop students' attitudes to learning in order to strengthen their self-efficacy beliefs and competencies. The project at Ulster actively promotes reflection as a capability that students can then use to adapt and respond to situations, thus enhancing their graduate abilities and employability. Our findings show that the PASS process can be used to 
encourage students to develop a capacity for reflection and is consistent with a more holistic view to employability.

However, the process of reflection will become a more integral part of our PASS training process and more effort will be invested in helping students to identify co-curricular and extra-curricular opportunities to further develop the skills covered as part of the PASS programme. Now that we have developed the resources we intend to repeat the evaluation perhaps across other disciplines to further explore the ideas emerging from this project. Here it may be of interest to note that the project continues to thrive in participating disciplines (i.e. the Schools of Law, Psychology and Computing and Intelligent Systems), it has also been extended to the School of Computing and Information Engineering and the School of the Built Environment. Recognising the value of the experience provided, the university, for four consecutive years, provided funding for a placement student to assist with the development of the scheme and associated projects. Interest in the role of PASS leader is also continuing to grow - an indication of the extent to which the experience is also valued by our students. This is particularly apparent in the School of Psychology where the number of students volunteering for the role has increased dramatically from 10 in 2010 to more than 40 in 2013. Further, students are also volunteering to spend their placement year working on associated projects in an unpaid capacity. Indeed, in the 2013/14 academic year three placement students were supported by the PASS process. Students clearly see the added value in becoming a PASS leader. The university also formally recognises the initiative with accreditation though the EDGE award. In a climate where graduate employability skills are in the spotlight, this proactive and developmental approach enhances career prospects and allows graduates to demonstrate to future employers a commitment to continuing personal and professional development.

\section{References}

Ashwin, P. (1994) 'The Supplemental Instruction leader experience, why Supplemental Instruction is not teaching: a student's perspective', in Rust, C. R. and Wallace, J. (eds.). Helping students to learn from each other: Supplemental Instruction (pp.8790). Birmingham, UK: Staff and Educational Development Association. 
Cranmer, S. (2006) 'Enhancing graduate employability: best intentions and mixed outcomes', Studies in Higher Education, 31(2), pp. 169-184.

Harvey, L. (2005) 'Embedding and integrating employability', New Directions for Institutional Research, 128, pp. 13-28.

Jarvis, J., Dickerson, C. and Stockwell, L. (2013) 'Staff-student partnership in practice in higher education: the impact on learning and teaching', Procedia - Social and Behavioral Sciences, 90, pp. 220-225.

Knight, P. T and Yorke, M. (2004) Learning, curriculum and employability in higher education. London: RoutledgeFalmer.

Lees, D. (2002) Graduate employability - literature review. University of Exeter. Available at:

http://www.qualityresearchinternational.com/esecttools/esectpubs/leeslitreview.pdf (Accessed: 14 November 2015).

National Centre for Universities and Businesses (2014) State of the relationship report 2014. Available at: http://www.ncub.co.uk/reports/sor.html (Accessed: 14 November 2015).

Morse, J. M. and Field, P. A. (1996) Nursing Research: the application of qualitative approaches. $2^{\text {nd }}$ edn. London: Chapman and Hall.

Pascarella, E.T. and Terenzini, P.T. (2005). How college affects students: (Volume 2) a third decade of research. San Francisco: Jossey-Bass.

Pegg, A., Waldock, J., Hendy-Isaac S. and Lawton R, (2012) Pedagogy for employability. York, UK: Higher Education Academy. Available at: http://oro.open.ac.uk/30792/ (Accessed: 14 November 2015).

Skalicky, J. and Caney, A. (2010) 'PASS student leader and mentor roles: a tertiary leadership pathway', Journal of Peer Learning (formerly The Australasian Journal of Peer Learning), Vol. 3(1), pp. 24-37. 
Wilson, T. (2012) A review of business-university collaboration, Department for Business, Innovation and Skills, UK Government. Available at:

https://www.gov.uk/government/publications/business-university-collaboration-thewilson-review

Yorke, M. (2006) Employability in higher education: what it is - what it is not. York, UK: Higher Education Academy. Available at:

http://www.employability.ed.ac.uk/documents/Staff/HEA-

Employability in HE(Is,IsNot).pdf

Yorke, M. \& Knight, P.T. (2006) Embedding employability into the curriculum. York, UK: Higher Education Academy. Available at:

http://www.employability.ed.ac.uk/documents/Staff/HEABriefings/ESECT-3-

Embedding employability into curriculum.pdf

\section{Author Details}

Amanda Zacharopoulou is a Senior Lecturer in the School of Law at Ulster University. She has been teaching for over twenty years and has an interest in legal education. She has occupied various teaching and learning roles within the university including that of Faculty Teaching and Learning Coordinator for Social Sciences. She is a trained PASS/SI Supervisor and has pioneered PASS (Peer Assisted Study Sessions) within the School of Law. She continues to develop student centred interventions within the School of Law designed to enhance the pre-entry, induction and transition experiences of law students. She is a Senior Fellow of the Higher Education Academy and a Fellow of the Centre for Higher Education Research Practice.

Melanie Giles is a Professor of Psychology and Head of School. She is also a Chartered Psychologist and a registered health practitioner with the HCPC. Her main research interests are in the area of health psychology and she is an active member of the Psychology Research Institute at Ulster. She also has a keen interest in learning and teaching. She has assumed a variety of administrative roles in this respect and is responsible for overseeing the quality of teaching and the development of enhancement 
activities. She is a trained PASS/SI Supervisor and is responsible for the introduction of the PASS peer mentoring scheme at Ulster. She is a Senior Fellow of the Higher Education Academy and a Fellow of the Centre for Higher Education Research Practice.

Dr Joan Condell is a Senior Lecturer in the School of Computing and Intelligent Systems in the Department of Computing and Engineering at Ulster University. She has been teaching maths and computing modules in Ulster since 1998. Joan has published work in computer imaging and maths, alongside robotics and health applications. This work includes publication in over 120 journal and conferences, successful completion of PhD students and the enhancement of student learning and engagement through peer assisted learning methods for maths (specifically PASS). She is a trained PASS/SI Supervisor. Her work has also extended in promoting computing as a career with initiatives such as wiCADET, a widening access project which involved teaching mobile app. development to local secondary pupils. 